\title{
Organizing Robotic Process Automation: Balancing Loose and Tight Coupling
}

\author{
Karen Osmundsen \\ Norwegian School of \\ Economics (NHH) \\ karen.osmundsen@nhh.no
}

\author{
Jon Iden \\ Norwegian School of \\ Economics (NHH) \\ ion.iden@nhh.no
}

\author{
Bendik Bygstad \\ University of Oslo \\ bendikby@ifi.uio.no
}

\begin{abstract}
Robotic Process Automation (RPA) is penetrating organizations at an accelerating rate. This trend is challenging the existing IT governance structures, because RPA usually is acquired and implemented by local business units, outside the control of the IT function. Consequently, how to organize and govern RPA initiatives is a topical issue. The recommendations from prior research are unclear, and there is a call for more research on this area. In this paper, we report from a study on RPA usage in three firms. In particular, we investigate the organizational consequences of having local business units manage the RPA initiatives. We make use of lightweight IT research as our analytical lens, contributing to research by unveiling the consequences and considerations of decentralized management of RPA.
\end{abstract}

\section{Introduction}

Robotic Process Automation (RPA) is not about some Frankensteinian creature wagging through the corridors of modern corporations, but about whitecollar software. What the software does, is dealing with the typical and relatively simple tasks of office workers; deciding a case matter by retrieving some information from various registers, using a set of rules to make the decision, and finally registering (or communicating) the decision to stakeholders [20]. Typical examples are applications for bank loans, insurance and tax cases, or customer enquiries. As one of our informants expressed, "we are not replacing humans with robots; we are taking the robot out of the human".

A key question for organizations implementing the technology is how to manage and organize the initiatives, in particular the relationship to the IT function. Should RPA be organized as a traditional IT project, with the IT professionals in a central role, or should the business people, with some support from the IT side, manage RPA?

To develop our argument we build on Bygstad's [3; 4] contribution on lightweight IT. The role of the IT function in the new digital landscape is being challenged and questioned, and research discusses how lightweight initiatives, such as RPA, should be organized. This was acknowledged in Gartner's [7] concept of 'bimodal IT', suggesting two different IT departments: one for traditional IT, focused on stability and efficiency, and one experimental and agile, focused on time-to-market and tight cooperation with business units. Bygstad [3] argued that firms should keep lightweight IT (for example RPA) and heavyweight IT (the central systems maintained by the IT function) separated; they should be loosely coupled, both in terms of organization, technology and standardization. He proposed that lightweight IT and heavyweight IT are not only different technologies, but also different knowledge regimes. Consequently, the innovative potential of digitalization is best served by having different organizations responsible for heavyweight and lightweight IT.

Willcocks et al. [20] studied one particular lightweight initiative, an RPA implementation in a major telecom company. They conclude that "it was only once the IT department became significantly involved, and satisfied, that RPA use escalated, and an enterprise RPA capability began to be built, supported by both business unit and IT resources" [20, p.22]. Willcocks et al. consider the involvement of the IT function as an important factor for RPA success, and they argue that IT should be brought on board early.

In this paper, we investigate these issues by studying the organization of RPA in three Norwegian companies. In particular, we investigate the consequences of loose coupling of RPA and the IT function in terms of organizational integration. Our research question is: 
What are the effects of organizing RPA in local business units?

The paper proceeds by explaining the technology, our analytical lens and our methodological approach. Further, the results from our case analysis are presented, followed by a discussion and lessons learned, whereas the conclusion finalizes the paper.

\section{Robotic process automation}

Robotic Process Automation (RPA) is a highly adopted automation solution within business today. The technology enables the automation of repeatable business processes, eliminating lower complexity tasks currently undertaken especially by back office teams. Common to most definitions, RPA is a software robot that mimics human activity by performing processes characterized by structured data, clear action rules, leading to unambiguous outcomes $[5 ; 6 ; 18]$. An RPA robot is assigned a logon ID and a password, and works in the same way as a human employee in solving recurring tasks.

Examples of RPA application include validating the sales of insurance premiums, generating utility bills, paying health care insurance claims, keeping employee records up-to-data, and generating news stories [13]. The typical robot collects structured data from one or several systems, performs some predefined calculations and registers the results into another system. The robot itself does not store any data. Developing a robot is different from traditional software development; the main task is to configure or 'teach' a standard RPA software package how to perform process activities. According to Lacity and Willcocks [11], RPA has three distinctive features compared to other automation tools:

- RPA is easily configured, and implementing it does not require that developers need programming abilities;

- RPA software is non-invasive, which refers to RPA software sitting on top of existing systems, accessing systems in the same way humans would; and

- RPA is enterprise-safe, indicating that IT requirements such as security, scalability and auditability are easily met.

Research finds that RPA has a profound effect on business performance. Software robots execute structured tasks precise and quickly, and firms experience improved service speed and quality, expanded service availability, and increased regulatory compliance [13]. According to a multiple case study, return of investment varied between 30 and 200 percent during the first year [15]. Another study reports on cost reductions between 25 and 40 percent [14]. It is also found that RPA affects parts of jobs more than entire jobs, and the effects on employment typically involves increased productivity and reductions in hiring or outsourcing, rather than layoffs of full-time employees [13].

However, not all processes are suitable for RPA, and a thorough assessment of potential candidates is necessary. Candidate processes should be routinized and standardized, their transaction volume or transaction value high and predictable, business rules must be clearly defined, and there should be no need for advanced cognitive assessments [12]. Choosing the wrong process for RPA is pointed out as an important reason for RPA projects' failure [14].

Firms organize RPA initiatives in different ways, but commonly outside the IT-department. Lacity and Willcocks $[10 ; 11]$ describe an organizing model and a development process, based on a central RPA center of excellence (CoE) and local RPA teams in business units. The local RPA teams suggest candidates for automation, the $\mathrm{CoE}$ assess the processes and decides, in collaboration with the business units, which processes that should be automated. A development team in the CoE designs, develops, verifies and deploys the robots. Then, responsibility is transferred to a control team within the CoE, which operates the robots, including monitoring and handling deviations. In addition, the control team manages change requests, which are handed over to the development team. In this way, a life cycle for implementation, maintenance, and continuous development of RPA is established.

\section{Analytical lens}

Digitalization is one of the main challenges companies face today [19], and companies respond to digitalization differently. Some firms are developing a digital business strategy, taking a top-down approach [2], while others are applying a laissez faire approach, allowing separate, uncoordinated digital initiatives to be developed ad hoc in local business functions $[3 ; 4$; 18].

As described above, RPA falls under a knowledge regime called lightweight IT [3], in contrast to the traditional heavyweight IT of the IT function. The differences are illustrated in table 1 . 
Table 1. Heavyweight and lightweight IT

\begin{tabular}{|l|l|l|}
\hline & Heavyweight IT & Lightweight IT \\
\hline Profile & $\begin{array}{l}\text { Back-end: Supporting } \\
\text { documentation of work }\end{array}$ & $\begin{array}{l}\text { Front-end: Supporting } \\
\text { work processes }\end{array}$ \\
\hline Systems & Transaction systems & $\begin{array}{l}\text { Process support, apps, } \\
\text { business intelligence }\end{array}$ \\
\hline $\begin{array}{l}\text { TT } \\
\text { architecture }\end{array}$ & $\begin{array}{l}\text { Servers, databases, } \\
\text { enterprise bus } \\
\text { technology }\end{array}$ & $\begin{array}{l}\text { Tablets, electronic } \\
\text { whiteboards, mobile } \\
\text { phones }\end{array}$ \\
\hline Owner & IT department & Meshworks \\
\hline $\begin{array}{l}\text { Development } \\
\text { culture }\end{array}$ & $\begin{array}{l}\text { Systematics, quality, } \\
\text { security }\end{array}$ & $\begin{array}{l}\text { Innovation, } \\
\text { experimentation }\end{array}$ \\
\hline Problems & $\begin{array}{l}\text { Increasing complexity, } \\
\text { rising costs, long } \\
\text { backlogs, delays }\end{array}$ & $\begin{array}{l}\text { Isolated gadgets, } \\
\text { security, privacy }\end{array}$ \\
\hline Discourse & Software engineering & Business innovation \\
\hline
\end{tabular}

Lightweight IT may be seen as complementary to heavyweight; it is well suited for the tasks that heavyweight IT often fails to support, i.e. the simple and immediate needs of a user. Lightweight IT typically supports work processes with simple applications or cheap technology [1]

The role of the IT function in digitalization is being challenged and questioned. Their traditional responsibility is to manage the infrastructure and the operation [19]. For years, however, firms have expected their IT functions to extend their roles from pure technology administrators to business developers [19]. Consequently, IT functions today are increasingly evaluated on responsiveness, fit with business needs and time to market [20]. In contrast, most IT managers are faced with a situation where their IT resources are occupied with maintaining the existing enterprise systems, leaving little time and resources for digitalization and new business development. The situation has led many firms to organize lightweight initiatives outside the IT function, but research is not conclusive whether this approach is constructive or not.

Bygstad [3] has studied the introduction of lightweight IT. In order to release its potential for business renewal and innovation, he argues that the development of lightweight IT should be kept separate from the IT function, the heavyweight regime. More specifically, he suggests that the relationship between lightweight and heavyweight IT should be based on loose coupling in terms of organization, technology, and standards. Regarding organizational integration, Bygstad [3] argues that the heavyweight culture is poorly suited for lightweight IT, which is characterized by rapid experimentation and innovation, and with high tolerance for failures. Moreover, few IT departments have either the resources or the time available to engage themselves in lightweight activities. Innovation is therefore best served by developing lightweight solutions outside the IT department. Alternatively, lightweight IT initiatives could be led by a separate unit in the IT department, in line with Gartner's notion of bimodal IT [7; 9]. In any case, heavyweight and lightweight solutions should be managed by separate and independent units.

Lightweight IT is in an early phase, and there is a call for more empirical research on how innovation processes involving lightweight IT should be governed [3].

\section{Method}

This study is part of a larger longitudinal research program on process automation and robotization in organizations. To investigate our research question, what are the effects of organizing RPA in local business units?, data from three Norwegian firms were analyzed; a leading regional bank, a government shared service center and a large international energy company. These cases were chosen for two reasons. First, digitalization has gained a strong foothold in these sectors where the potential for automation is large and the use of RPA is spreading in a rapid pace. Second, the companies in question are early adopters of RPA in Norway, giving them knowledge of issues occurring during initiation and implementation phases, in addition to having experienced the consequential effects.

We conducted personal interviews with employees who at different levels have worked directly with, or been affected by, the RPA initiatives. An overview of interviewees is presented in table 2 . We chose a semistructured interview format; we used an interview guide as a basis, and asked supplementary questions when necessary. Most interviews were recorded and transcribed. If clarifications were needed, short summaries were sent to the interviewees for approval in order to ensure correct interpretation and to correct potential misunderstandings. 
Table 2. Interviewees

\begin{tabular}{|c|c|c|c|}
\hline $\begin{array}{c}\text { Time of } \\
\text { interviews }\end{array}$ & Spring '17 & $\begin{array}{c}\text { Autumn '17 \& } \\
\text { Spring '18 }\end{array}$ & $\begin{array}{c}\text { Autumn '17 \& } \\
\text { Spring '18 }\end{array}$ \\
\hline $\begin{array}{c}\text { No. of } \\
\text { interviewees }\end{array}$ & 7 & 8 & 11 \\
\hline \multirow{7}{*}{$\begin{array}{c}\text { Role of } \\
\text { interviewees }\end{array}$} & The bank & $\begin{array}{c}\text { The } \\
\text { government } \\
\text { shared service } \\
\text { center }\end{array}$ & $\begin{array}{c}\text { The energy } \\
\text { company }\end{array}$ \\
\cline { 2 - 4 } & $\begin{array}{c}\text { Process } \\
\text { designer (1) }\end{array}$ & $\begin{array}{c}\text { Project owner } \\
\text { (1) }\end{array}$ & $\begin{array}{c}\text { Project owner / } \\
\text { manager (3) }\end{array}$ \\
\cline { 2 - 4 } & $\begin{array}{c}\text { Process } \\
\text { identifier (3) }\end{array}$ & $\begin{array}{c}\text { Process } \\
\text { identifier (1) }\end{array}$ & $\begin{array}{c}\text { Process } \\
\text { identifier / } \\
\text { designer (4) }\end{array}$ \\
\cline { 2 - 4 } & IT manager (1) & $\begin{array}{c}\text { Project } \\
\text { manager (2) }\end{array}$ & $\begin{array}{c}\text { Employee } \\
\text { affected by } \\
\text { RPA (2) }\end{array}$ \\
\cline { 2 - 3 } & manager (2) & \multicolumn{2}{|c}{} \\
\cline { 2 - 3 } & $\begin{array}{c}\text { Robot } \\
\text { configurator (1) }\end{array}$ & $\begin{array}{c}\text { Robot } \\
\text { configurator (2) }\end{array}$ & \multicolumn{2}{|c}{} \\
\hline
\end{tabular}

The data analysis was conducted in two steps [16]. First, timelines and a case descriptions were constructed based on the data obtained. Then, with Bygstad's lightweight integration framework as our theoretical lens [3], we conducted a comprehensive analysis of the cases, investigating organizational and governance issues.

\section{The cases}

\subsection{The bank}

The bank is a regional bank operating in the western region of Norway, providing regular banking, financing, and insurance services. The RPA initiative arose in 2015, with the first implementations in 2016. The initiative was mainly driven by the desire to renew the bank's business processes, and the failure of the bank's central IT function and systems to meet this desire. The RPA approach was chosen because the investments required for this technology were small and the prospect of producing results quickly appeared prominent. The main objectives for the RPA initiative were to free up cognitive capacity and time by automating simple, often high-volume, rule-based tasks and to ensure streamlined and standardized business processes.

An RPA team was established in the department for Process Optimization, consisting of both internal and external personnel. The internal resources consisted of a project manager, process designers, robot configurators and an IT manager with the mandate of establishing boundaries between RPA and the IT function. The external consultants' tasks were to configure robots, and to train the internal resources in this activity. Examples of processes that have been automated are the establishment of corporate accounts and the establishment of savings accounts for young home buyers in a mobile bank. As of April 2017, the robots had performed approximately 100,000 tasks in various business processes.

\subsection{The government shared service center}

The government shared service center has 400 employees servicing governmental institutions with accounting and salary solutions. At present, their workload is increasing as more state administrations are turning to them for their services. In 2014, under the pressure of running more efficiently, the shared service center set out to investigate possible solutions for improved efficiency and simpler ways of working. In this process, information about RPA was collected, and the company decided to run a pilot project in 2016 to test software and consider the possibilities for RPA. The pilot project members consisted of a project manager and representatives from both the business units and the IT function. Together with external consultants, they mapped potential processes suited for RPA and tested RPA solutions with two different software tools. In 2017, the company decided to purchase a software tool and start the RPA implementation project.

As of October 2017, nine processes had been identified as well suited for RPA and chosen for implementation. The processes chosen were those that included a high degree of manual, repetitive and rather easy tasks that were executed frequently in the department, taking up a lot of the employees' time, such as account reconciliation and creating new vendor accounts in the systems. As of April 2018, the robots were partly in production, meaning that the robot configurators and external consultants were still working on some final changes on some of the processes, whereas others were fully implemented.

\subsection{The energy company}

The energy company is an international firm operating mainly within the oil and gas sector. The company started experimenting with RPA in late 2016, where the purpose was to 'play and learn'. The formal RPA initiative was launched in early spring 2017. Soon, a fast-growing interest in RPA throughout the organization emerged. With RPA, the overall purpose is to relieve employees from dull and repetitive tasks, as our interviewee commented: 'we are not replacing 
humans with robots; we are taking the robot out of the human'.

Apart from a few central persons coordinating the initiative firm wide and controlling the software licenses, the company initially decided not to establish a central RPA team in the organization. They wanted a more unstructured approach, putting the users in local business in the front seat by educating them as business analysts and RPA developers. Following this perspective, as of May 2018, approximately 350 employees from various business units have received RPA foundation training. In January 2018, the company decided to establish an RPA team with five fulltime employees, despite their prior aversions against this. The purpose of the new team was to support the RPA work in the local business units. Robotization - analyzing the processes and developing the robots - is still being carried out by line employees in the business units. The goal for the RPA initiative was to have 50 robots in operation during 2017 - a goal the company reached, estimated to have resulted in automation of 1200 manual working hours per month. Following this achievement, the goal for 2018 is to automate 200000 manual working hours.

\section{Case analysis}

Bygstad [3] suggests loose coupling of lightweight and heavyweight IT. All three case organizations organize RPA in the business units, loosely coupled from the IT function. Such loose coupling gives rise to advantages and challenges in the organizations.

\subsection{Loose organizational coupling of RPA}

'We do not call RPA an IT project'.

In all three cases, those in charge were quite conclusive about organizing RPA outside the realm of the IT function. The energy company and the shared service center took a decentralized strategy, to build up competence and skills locally, and thus letting the business units develop the robots themselves. Being a large international company, the energy company had employees working on implementing RPA in different business areas and in several countries. The central RPA team, which included representatives from the IT function and an external consultant, was there to coordinate the various initiatives, organize training sessions and, if necessary, give assistance, but the managing principle was that the local business units themselves were responsible.

At the government shared service center, RPA was organized by establishing a joint program by the two major business units, reporting to the director of the first. The program members had either managerial or operational roles in the organization. The RPA team consisted of representatives from the business units, and was responsible for managing the program, developing and maintaining the RPA solutions for selected processes within the department, providing sufficient and relevant training, as well as advocating for RPA in the remaining departments of the company. In addition to internal resources, the RPA team also consisted of developers from an external consultancy firm. The external consultants were key to the first phases of the implementation process, in both developing RPA solutions and training the internal resources. Gradually, the internal resources would take over the tasks of the external resources, and become more self-driven and independent without external support. Organizing the RPA team and keeping the developers of the solutions outside IT was a deliberate choice, and as the project owner explained: 'There are a number of regulations and rules we have to comply with, and it is important for us that we involve employees who actually know the processes, to ensure that we still comply with any regulations...'

The bank, in contrast, decided to build up one central RPA team. Organizationally, the team was located in an existing unit for process optimization. Line employees were recruited to build the robots. This decision was not without debate. The main question was whether RPA is considered an ordinary programming job for the IT function or as an innovative tool for business units working on process improvement. The response from the IT function was characterized by negativity. As one member of the RPA team expressed it: 'The aversion in the IT function against robots is deeply rooted - they are of the opinion that robots are a poor man's integration tool. Robots are only a temporary IT solution, they say. They would not even name it an IT solution. If it were up to them, they would prohibit robots.'

From the IT function's perspective, RPA is programming. IT therefore considered it as more efficient to have all the programmers gathered in the IT function, instead of out in the organization. The conflict also revolved around professional standards. The IT function was concerned about RPA developers not having a proper IS education, and did not apply the methods and the best practices educated IS developers use. The IT function also had the opinion that the tasks of the RPA team should be solved with system integration and more advanced programming, perceiving RPA team members as amateurs. An RPA team member described the attitudes amongst IT colleagues towards his work in the RPA team: 'They perceived me as a fool, and that I did not realize how stupid I was'. 
The tension between the IT function and the RPA team also had another cause. For years, process optimizing had been the responsibility of the IT function. Consequently, the IT function saw process improvement and IS development as closely related. There was, however, an opinion that IT had failed in this respect. As one of the drivers for RPA was the desire to renew the bank's business processes, the bank saw the opportunity to increase the speed of process improvement by placing RPA outside of IT. The RPA team would then be able to redesign the bank's processes, without having to bring each idea through the IT function's lengthy priority loop.

\subsection{Advantages of loose coupling}

Building enthusiasm for digitalization. In all three cases, the deep involvement of local employees in the RPA initiatives generated enthusiasm for technology and digitalization in the business units. The local RPA configurators expressed excitement regarding their new tasks, highlighting their own development and the opportunity to take part in the organizations' digitalization efforts. In the energy company, the configurators expressed how they wanted to be part of the RPA initiatives from the beginning: '(...) when we realized that we could get this opportunity, we wanted to take it: we could develop the small things that we saw could make our workday better. If we didn't do it, then we would have to bring in someone every time we needed an improvement, so that's why we wanted the competency ourselves.'

The employees in the local business units in all organizations acknowledged that they now had access to a tool for everyday-improvement, and more easily realized how different business processes could become subject for improvement and digitalization. As the local employees worked with RPA, they started realizing the potential of the tool, and how it could be applied to make processes more efficient. One interviewee at the energy company pointed out that: '(...) the most important thing now, in the phase we are in now, is simply to see the potential in the tool. The more you work with it, the more you see.' Following this, an interviewee in the shared service center similarly pointed out that: "we now see ways to improve processes more easily than before, which can lift the process further.'

Further, employees realized how they could employ the RPA software, and the toolbox that follows, to make improvements themselves, without going through the IT function. As one of the interviewees in the energy company explained: '(...) we could fix the small things that we reported to IT before, but which we never got through because it either costed too much or wasn't prioritized.'

The RPA-initiative was also pointed out, in the shared service center, to bring to light a conversation about digitalization, beyond robotization, in the business units: 'This gives more of us an opportunity to keep up, develop ourselves, and develop the organization.'

Building local ownership. By organizing the RPA initiatives outside of IT, the case organizations were able to better involve the persons who actually know the processes - the local employees working in the processes on a daily basis. An interviewee in the shared service center explained the importance of business unit employees' involvement in the RPA project: 'There is an advantage in having [RPA configurators with] background from IT / programming, but I think it is almost as important with good knowledge of the processes, so you know a little about each part of a process, and how things are interrelated.' The importance of involving employees working in the processes on a daily basis was also emphasized in the bank. All interviewees stated that the RPA team should sit in the business, and that the RPA capability should be built internally. In the bank, the importance of involving employees from the local business units was highlighted in relation to both the mapping and development of the RPA solutions: 'It is incredibly important that the people mapping the processes have an understanding of the business (...) they need to understand the importance of every little detail.'

In the energy company, the importance of involving employees from the business units was also highlighted in relation to the maintenance of the RPA solutions: '(...) I think that ownership to your own robots is extremely important to understand them. And we are the only ones who can understand and know the processes good enough to see if things work or not. IT will not be able to do that - IT could tell us that there is something wrong, but only the business can tell what is wrong.'

Such involvement of process "experts" further enhances these employees' understanding of the processes they are involved in, and their own work routines and responsibilities. The RPA initiatives require continuous mapping of, and insight into, the business processes in the organizations. Hence, RPA enabled employees to think more thoroughly through how they work, and how to improve their work routines. One interviewee in the energy company commented that 'in order to make changes, you have to think a bit on what we are doing here and how we do it.' 


\subsection{Challenges of loose coupling of RPA}

Lack of control mechanisms. One of the main challenges with keeping the RPA initiatives inside the local business units was found to be a lack of controlling mechanisms to coordinate and prioritize the different RPA initiatives. Without a consistent form of central governance, opening for local RPA initiatives would over time lead to too many separate initiatives going on simultaneously, and that the organizations lose track of the initiatives. One interviewee in the energy company commented that: 'the challenge with RPA is that, if you make too many solutions like that, you get a sort of spaghetti-solution which you easily can lose track of.' Lack of control mechanisms also led to the organizations eventually realizing that they have spent a lot of time and resources on automating the wrong processes. Without central prioritization of RPA initiatives, the business units typically prioritized the small and easy processes, where one quickly could see improvements and results, rather than the processes most important for the organization as a whole. One interviewee in the energy company commented: 'you spend a lot of time on an RPA case before it is "stopped". So we should have control mechanisms in place earlier, so that we don't use a lot of time on the wrong things.'

Further, with a lack of central control, we found that candidate processes were only assessed within the local business units. As one of the interviewees in the energy company commented: 'at this point in time, it is kind of like each department thinks a bit silo, for themselves, that they should solve their own tasks.' Such departmental perspective on working with RPA eventually reinforces a silo mentality in the organizations. A more central approach to governance of the RPA initiatives, would lead to more efficient coordination across departmental boundaries.

At the bank, which has gained the most experience with RPA, the maintenance of the robots also emerged as a critical task in need of better control. Gradually, the RPA team experienced that the virtual robots required a lot more maintenance than initially expected. The RPA project manager commented: 'You always underestimate the complexity of things, even if it is simple. There is more need for monitoring and maintenance than we thought one year ago. (...) We just wanted to get started, and our focus was on delivering solutions.'

Having local business units mainly engaged in the RPA initiatives also led to pressure related to resources and capacity in the business units. Many of the employees involved in the RPA initiatives in the organizations studied, had to do so in addition to their ordinary work tasks. Without any central governance mechanisms, the employees had to prioritize their time themselves, and sometimes the daily operations suffered from these prioritizations. As the volume and scope of RPA initiatives increased, the resources with RPA expertise became even more limited and constrained.

Lack of end-to-end process view. Throughout the cases, our analysis shows that RPA initiatives were initiated and developed for processes within departments, without a holistic perspective of how processes are part of and affect other parts of the organization. In the shared service center, one interviewee acknowledged this issue: 'we probably should have looked at the processes more comprehensively. It comes down to time and prioritizations'. Another interviewee followed this up with: '(...) we certainly see that overarching look would be better, but that is a much bigger job, requires much greater changes of processes, mindset, systems, etc.' Because RPA was organized locally, the focus was on intra-departmental processes, without considering the whole organization.

Without a holistic perspective of organizations' processes, the focus became on implementing RPA to sub-processes, rather than the end-to-end processes in the organizations. Many of the "processes" the robots were taking over were actually sub-processes conducted within individual business units. One interviewee commented: 'A lot of us don't think "process", to put it like that. (...)You don't really manage to raise yourself high enough to see the whole process, because you are inside your own bubble.' As long as RPA initiatives are organized locally, in the individual business units, the organizations will experience a hard time fully grasping the end-to-end processes in the organization. As pointed out by an interviewee in the energy company: 'It's the activities that are interesting, and eventually we will be able to look at the processes. But I don't think we have come so far that we can go there yet (...)'

To summarize, the organizations studied in these cases all employ a form of decentralized strategy for organizing RPA. We identified both advantages and challenges associated with having the RPA initiatives taking place in the local business units, which are summarized in table 3 .

Table 3. Advantages and challenges of loose coupling

\begin{tabular}{|l|l|}
\hline Advantages & Challenges \\
\hline $\begin{array}{l}\text { Building enthusiasm } \\
\text { for digitalization }\end{array}$ & $\begin{array}{l}\text { Lack of control } \\
\text { mechanisms }\end{array}$ \\
\hline $\begin{array}{l}\text { Building local } \\
\text { ownership }\end{array}$ & $\begin{array}{l}\text { Lack of end-to-end } \\
\text { process view }\end{array}$ \\
\hline
\end{tabular}




\section{Discussion and lessons learned}

The research question for this study is what are the effects of organizing RPA in local business units? The literature suggests that RPA falls under the category of lightweight IT, and that lightweight IT should be loosely coupled from heavyweight IT [3]. The possibilities for innovation is often highlighted as a main benefit of lightweight IT and loose coupling. However, we do not find that RPA (as an example of lightweight IT and loose coupling) is characterized with innovation, but rather regards automation of existing, "boring" tasks. Further, although our analysis shows that local organization of RPA has some clear advantages, the challenges of such organization are also evident. These challenges are related to lack of control and lack of end-to-end business view. An interesting question is whether it is possible to initiate measures to reduce these challenges, and at the same time maintain the advantages.

If the organization's intention of organizing RPA in local business units, is to accelerate the pace and volume of RPA initiatives, and to enhance enthusiasm towards digitalization, loose coupling is appropriate. Nonetheless, the organization must be aware of the challenges that follow such organization of RPA. One approach then, is to organize RPA loosely coupled with IT for a while to foster innovation and local enthusiasm in the beginning, and tighten the relationship at a later point in time.

Another approach is, while still keeping the RPA initiatives in the local business units, to introduce a central body for control, coordination, and prioritization, and to keep track of RPA initiatives in the entire organization. This central body does not necessarily have to be the IT function, but someone with an overarching view of the RPA initiatives across the entire organization, similar to a suggestion from one of the interviewees to 'formalize and reinforce the $R P A$ projects into a permanent "RPA center of excellence".' In this case, the organization needs to consider how they can introduce such mechanisms and still maintain the local enthusiasm and ownership.

Which approach for organizing RPA is suitable for an organization, needs to be considered based on several aspects, such as the scope of the RPAinitiatives, the size of the company, the type of organization, and how important the organization considers local enthusiasm, ownership and control.

The approaches mentioned above only serve to solve the first challenge we identified in the cases, lack of control, and does not deal with the second challenge, lack of end-to-end process view. The RPA technology, with its characteristics, falls under the Business Process Management (BPM) umbrella. However, we find that local organization of RPA challenges central principles of BPM. First, RPA is applied to subprocesses, rather than end-to-end processes, which is central to BPM. Second, and as a consequence of the first, the organizations become adherent to an exploitive practice.

As pointed out in the case analysis, managing RPA in the business units leads to a lack of focus on end-toend processes, i.e. processes across an enterprise that create customer value [8]. Truly addressing end-to-end processes is an important principle for BPM. An endto-end process view implies a focus on high-leverage aspects of the organization leading to great results and impacts, and an understanding of how processes cross business unit boundaries [8]. An end-to-end perspective on processes also enables explorative process management. Explorative process management focuses on renewal and future growth, rather than the existing [17], which should also be an important aspect of RPA. According to Rosemann [17], explorative process management is crucial for organizations challenged by the rapid development of digital technology. Without an end-to-end perspective on processes, the organizations will have a hard time freeing themselves from yesterdays practice, and experience challenges in meeting industry changes and customer demands.

In the organizations we studied, RPA initiatives were mapped and implemented for individual subprocesses, rather than end-to-end processes. Further, the focus was exploitive [17], focusing on implementing RPA on existing processes, rather than explorative [17], focusing on improving the processes to better embrace the options that come with RPA and to develop the way the organizations want to work in the future. BPM further emphasizes that the process owner is responsible for the process from start to finish. Together with the process roles, the process owner is responsible to develop the process and initiate efforts for process improvement. With RPA, we found a practice in the organizations studied where the individual business units initiated the process improvement initiatives (RPA). Moreover, this was done without consulting the process owner, or considering the process in an end-to-end perspective or explorative way. Such practice could potentially be destructive for BPM and end-to-end process improvement.

This exploitive perspective on sub-processes could stem from the fact that the organizations only have been working with RPA for a limited period. However, we argue that this will remain an issue as long as RPA 
is organized in the local business units, and, over time, this could be directly violating the principles of BPM.

\section{Conclusion}

Digitalization challenges the traditional role of the central IT function. In this study of robotic process automation (RPA) in a large bank, a government shared service center and an energy company, we investigated the loose coupling of RPA and IT in the organizations. We found that there are several advantages with organizing and managing RPA initiatives outside of the IT function. Such loose coupling of RPA and IT, however, comes with some challenges. The challenges are mainly related to lack of control and lack of end-to-end process view.

We present an approach to dealing with the first challenge, and discuss how RPA, as it is practiced today, could be destructive for Business Process Management (BPM).

\section{References}

[1] Alemdar, H., \& Ersoy, C. (2010). Wireless sensor networks for healthcare: A survey. Computer

Networks, 54(15), 2688-2710.

[2] Bharadwaj, A., El Sawy, O. A., Pavlou, P. A., \& Venkatraman, N. (2013). Digital business strategy:

Toward a next generation of insights. MIS Quarterly, 37(2), 471-482.

[3] Bygstad, B. (2015, May 27-29). The Coming of Lightweight IT. Paper presented at the ECIS European Conference on Information Systems, Münster.

[4] Bygstad, B. (2016). Generative innovation: a comparison of lightweight and heavyweight IT. Journal of Information Technology, 32(2), 180-193.

[5] Davenport, T. H., \& Kirby, J. (2016). Just How Smart Are Smart Machines? MIT Sloan Management

Review, 57(3), 21-25.

[6] Fung, H. (2014). Criteria, use cases and effects of information technology process automation (ITPA). Advances in Robotics \& Automation, 3(3), 1-10.

[7] Gartner. (2014). Bimodal IT: How to Be Digitally Agile Without Making a Mess. Retrieved from https://www.gartner.com/doc/2798217/bimodal-it-digitallyagile-making

[8] Hammer, M. (2002). Process Management and the Future of Six Sigma. MIT Sloan Management Review 43(2), 26-32.
[9] Horlach, B., Drews, P., \& Schirmer, I. (2016). Bimodal IT: Business-IT Alignment in the Age of Digital Transformation. Paper presented at the Proceedings of Multikonferenz Wirtschaftsinformatik

(MKWI), Technische Universität Ilmenau.

[10] Lacity, M., \& Willcocks, L. P. (2015). Robotic Process Automation at Telefonica O2. MIS Quarterly

Executive, 15(1), 21-35.

[11] Lacity, M., \& Willcocks, L. P. (2015). Robotic Process Automation: The Next Transformation Lever for Shared Services. London School of Economics Outsourcing Unit Working Papers (7).

[12] Lacity, M.C., Willcocks, L.P. \& Craig, A. (2015). Robotic Process Automation: Mature Capabilities in the Energy Sector. London School of Economics Outsourcing Unit Working Papers (15/06), 1-19

[13] Lacity, M. C., \& Willcocks, L. P. (2016). A New Approach to Automating Services. Management Review, 58 (1), 41-49

[14] Lamberton, C. (2016). Get ready for robots. Why planning makes the difference between success and disappointment. Retrived June 11. 2018 from https://www.ey.com/gl/en/industries/financial-

services/insurance/ey-get-ready-for-robots

[15] Lhuer, X. (2016). The next acronym you need to know about: RPA (robotic process automation. Retrived June 11. 2018 from https://www.mckinsey.com/businessfunctions/digital-mckinsey/our-insights/the-next-acronymyou-need-to-know-about-rpa

[16] Miles, M. B., \& Huberman, A. M. (1994). Qualitative Data Analysis (2nd ed.). Thousand Oaks: Sage Publications.

[17] Rosemann, M. (2014). Proposals for Future BPM Research Directions. Proceedings of the second Asia Pacific Business Process Management Conference. Quyang, C. and Jung, J.-Y. (eds.) Lecture Notes in Business Information Processing, Springer Verlag, Brisbane, 1-15.

[18] Sia, S. K., Soh, C., \& Weill, P. (2016). How DBS Bank Pursued a Digital Business Strategy. MIS Quarterly Executive, 15(2), 105-121.

[19] Singh, A., \& Hess, T. (2017). How Chief Digital Officers Promote the Digital Transformation of their Companies. MIS Quarterly Executive, 16(1), 1-17.

[20] Willcocks, L. P., Lacity, M., \& Craig, A. (2015). The IT Function and Robotic Process Automation. Retrieved May 18, 2016, from http://eprints.lse.ac.uk/64519/1/OUWRPS_15_05_published. pdf 